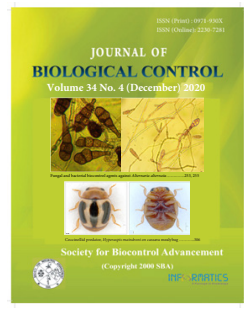

\title{
Deciphering the network of interconnected pathways of Chaetomium globosum antagonistic related genes against Bipolaris sorokiniana using RNA seq approach
}

\author{
K. DARSHAN*, RASHMI AGGARWAL, BISHNU MAYA BASHYAL and M. HARITHA MOHAN \\ Fungal Molecular Biology Laboratory, Division of Plant Pathology, ICAR - Indian Agricultural Research Institute, New Delhi \\ - 110012 , India \\ *Corresponding authorE-mail:darshuuas@gmail.com
}

\begin{abstract}
Chaetomium species are known as potential biocontrol agents against phytopathogens due to their multiple antagonistic mechanisms. Plant disease is controlled by Chaetomium exhibit complex interactions against plant pathogen under varied conditions. Previously, mycoparasitism and antibiosis have been reported as most effective mechanism exhibited by the C. globosum against Bipolaris sorokiniana. In the present study, the examination of major biosynthetic pathways underlying Chaetomium globosum biocontrol activity was elucidated. It was shown that the pathways related to biosynthesis of secondary metabolites, hydrolytic enzymes and other key regulator genes were involved in production of hydrolytic enzymes and antifungal metabolites. We identified various genes of biological function with significant $\log 2$ fold change such as phosphoribosyl aminoimidazole carboxylase (9.693), protease (8.18), cyanate hydratase (Cyanase) (6.7), Fe2OG dioxygenase domain-containing protein (5.9), superoxide dismutase (5.55), glycosidase (5.34), carboxylic ester hydrolase (5.27), alpha-1,2-Mannosidase (4.44), alpha-1,4 glucan phosphorylase (3.99), endochitinase (3.87), P53-like transcription factor (Fragment) (3.55), metalloprotease (3.4), polyketide synthase (3.35), Catalase-peroxidase (CP) (3.14), protein kinase domain-containing protein (3.18) and glutamate decarboxylase (2.1) which are involved in biosynthesis of secondary metabolites, polyketide synthase, antibiotic, hydrolytic enzymes and putative fungistatic metabolites. This data provides a good foundation for continued researches into C. globosum Cg2 biocontrol activity for facilitating widespread application under the field conditions.
\end{abstract}

KEY WORDS: Bio-control, Bipolaris sorokiniana, Chaetomium globosum, CNV, interconnected pathways, secondary metabolites

(Article chronicle: Received: 02-12-2020, Revised: 28-12-2020, Accepted: 30-12-2020)

\section{INTRODUCTION}

In recent years, biocontrol strategy has received tremendous attention in controlling plant diseases due to hazardous effects of pesticides and agrochemicals on ecosystem. There are about 35 genera of fungal and bacterial species, which have been used as biocontrol agents against various plant pathogens. Plant pathogens cause significant losses to agricultural products. Traditional chemical control methods are not absolutely efficient to minimize these losses. Biological control of plant pathogens can be highly effective especially with potentials of antagonists on pathogenic fungi. Chaetomium is one of the extremely familiar genus of Pyrenomycetes (Ascomycotina) encountered on various agricultural commodities and various species of the genus Chaetomium are used as biocontrol agents against several plant pathogenic fungi like Bipolaris oryzae, Rhizoctonia solani, Fusarium fujikuroi, Fusarium graminearum, Bipolaris sorokiniana, Tilletia indica, Alternaria triticina and Alternaria alternata. The genus contains more than
200 species all characterised by dark coloured perithecia with short neck, which are clothed with irregularly coiled or tightly spiralled hairs or with stiff, simple or branched setae (Doveri, 2013; Wang et al., 2016). It is common colonizer of soil and cellulose containing substrates.

Among various species, Chaetomium globosum is a ubiquitous filamentous fungus having biological control properties and reported effective in reducing damage caused by seed rot and damping off, of several seed borne and soil borne plant pathogens like Pythium ultimum, Alternaria raphani, A. brassicicola, Fusarium spp. and B. sorokiniana (Harman et al., 1978; Vannacci and Harman, 1987; Aggarwal et al., 2004). Antagonistic mechanisms of C. globosum fungus are exerted through different studies. Chaetomium globosum $\mathrm{Cg} 2$ strain presented the highest antagonistic activity against Bipolaris sorokiniana with the inhibition of $75.54 \%$. Chaetomium globosum mycoparasitizes and produces antifungal metabolites that helps in lysis of cell wall of the pathogen. Among them, competition for space 
and nutrients (Vannaci and Harman, 1987) as well as mycoparasitism (Mandal et al., 1999) are well established. At the microscopic stage, the pathogen (Bipolaris sorokiniana) mycelium shows malformed and deformed conidia with distorted walls, lysis and formation of holes in the conidial wall, which significantly inhibited germination of conidia and hyphal elongation (Mandal et al., 1999; Biswas et al., 2000; Moya et al., 2016; Darshan et al., 2020). Transcriptomic studies of $C$. globosum against B. sorokiniana reported the significant expression of genes encoding secreted proteases such as aminopeptidase (GO:0004177), metallopeptidase (GO:0008237), aspartic-type endopeptidase (GO:0004190) and serine-type carboxypeptidase (GO:0004185) which may involve in the degradation of fungal cell walls and plasma membrane proteins (Darshan et al., 2020). Further, antibiosis was also reported as a most prevalent antagonistic mechanism of C. globosum against B. sorokiniana (Aggarwal et al., 2004). Aggarwal et al. (2013) have characterized the antifungal metabolites of C. globosum and identified antifungal compounds like chaetoglobosin A and cochliodinol.

High-throughput sequencing is a powerful tool for identifying genes or genetic variants associated with phenotypes, including components of C. globosum antagonisms. Signalling networks regulate biology of cells and organisms in normal and diseased states. Transcriptomicsbased networking pathways search will fundamentally change our understanding of signalling networks. Until now, only very little information is available on these interconnected pathways during Cg2-BS112 interaction. The expression of genes associated with biocontrol appears to be regulated by intracellular signal transduction pathways, which are activated by the binding of host-derived ligands to as yet unidentified receptors. The elucidation of these pathways has recently begun and has confirmed the involvement of highly conserved signalling components. Therefore, present study aims to identify the interconnected pathways of Chaetomium globosum antagonistic related genes against Bipolaris sorokiniana using RNA seq approach.

\section{MATERIALS AND METHODS}

\section{Maintenance of biocontrol agents and plant pathogens}

The C. globosum strain $\mathrm{Cg} 2$ isolated earlier from wheat leaf surface (Mandal et al., 1999) available in fungal molecular biology lab, Division of Plant Pathology, Indian Agricultural Research Institute (IARI), New Delhi was used for the present investigation.

The pathogens Bipolaris oryzae, Rhizoctonia solani, Fusarium fujikuroi, Fusarium graminearum, Bipolaris sorokiniana, Tilletia indica, Alternaria triticina and Alternaria alternata previously characterized as a highly virulent isolates of the pathogens were used as target in our experiments. The strains were grown on Potato Dextrose Agar (PDA) at $25 \pm 2{ }^{\circ} \mathrm{C}$. The pure cultures of the fungi were obtained by single spore isolation and the cultures were maintained on PDA slants at $25 \pm 2^{\circ} \mathrm{C}$ with periodic sub culturing for the further studies.

\section{Dual culture assay of $C$. globosum against rice and wheat fungal pathogens}

The antimicrobial capacity of the selected strain was evaluated by dual solid culture assay in Petri plates (Dal Bello et al., 1994). The mycelial disc of C. globosum (9 $\mathrm{mm}$ diameter) was placed at one side of Petri dish $(1 \mathrm{~cm}$ from the edge of the plate) containing $10 \mathrm{ml}$ PDA medium. Subsequently, mycelial disc (9 mm diameter) of seven days old culture of different above-mentioned pathogens mycelial plug was placed $1 \mathrm{~cm}$ away from the margin of the opposite side of the same plate. Three replicates of each pathogenantagonist interaction were done. The control plates were also maintained without an antagonist. The inoculated plates were sealed with kiln film and kept for incubation at room temperature $\left(25 \pm 2^{\circ} \mathrm{C}\right)$ till control plate fully covered the plate ( 9-11days). Subsequently, the radial mycelial growth of the pathogen and per cent reduction over control was calculated by using the formula following:

$$
\begin{array}{cccc}
\begin{array}{c}
\text { Percent inhibition over } \\
\text { control }
\end{array} & \begin{array}{c}
\text { C-T } \\
------
\end{array} & \text { C } & 100
\end{array}
$$

Where,

C- Mycelial growth of pathogen in control

T- Mycelial growth of pathogen in dual plate

\section{RNA isolation and illumina sequencing}

The total RNA was extracted from frozen mycelial samples drawn from the interaction zone of C. globosum against B. sorokiniana using Qiagen RNeasy Plant Mini Kit. The procedure for isolation of RNA and procedures for Illumina Sequencing was described in our previous study (Darshan et al., 2020). The work flow of transcriptome sequencing by Illumina platform is presented in Figure 1. The cDNA library sequencing was performed on the Illumina highthroughput sequencing platform (HiSeqTM2500) to obtain $2 \times 150$ bp Pair-end (PE) reads. The raw Illumina sequence reads related to $C$. globosum $(\mathrm{Cg} 2 \mathrm{Control})$, B. sorokiniana (BS112 control) and their interactions (Cg2-BS112) with two replicates were deposited at Sequence Read Archive (NCBI/SRA) under the accession numbers, SRR11305503; SRR11305502; $\quad$ SRR113055501; $\quad$ SRR113055500; SRR11305499; SRR11305498. The transcriptome data are deposited in BioProject in GenBank via Bioproject number PRJNA612183 accessible at: https://www.ncbi.nlm.nih.gov/ bioproject/ PRJNA612183/(Darshan et al., 2020). 
1. Total RNA extraction and mRNA purifications
2. ds cDNA synthesis

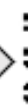

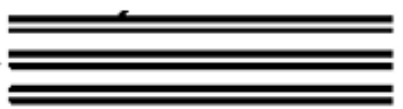

3. Enzymatic fragmentation

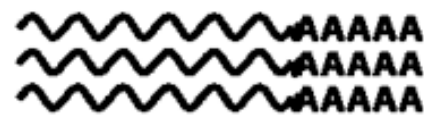

\section{$\Longrightarrow$}
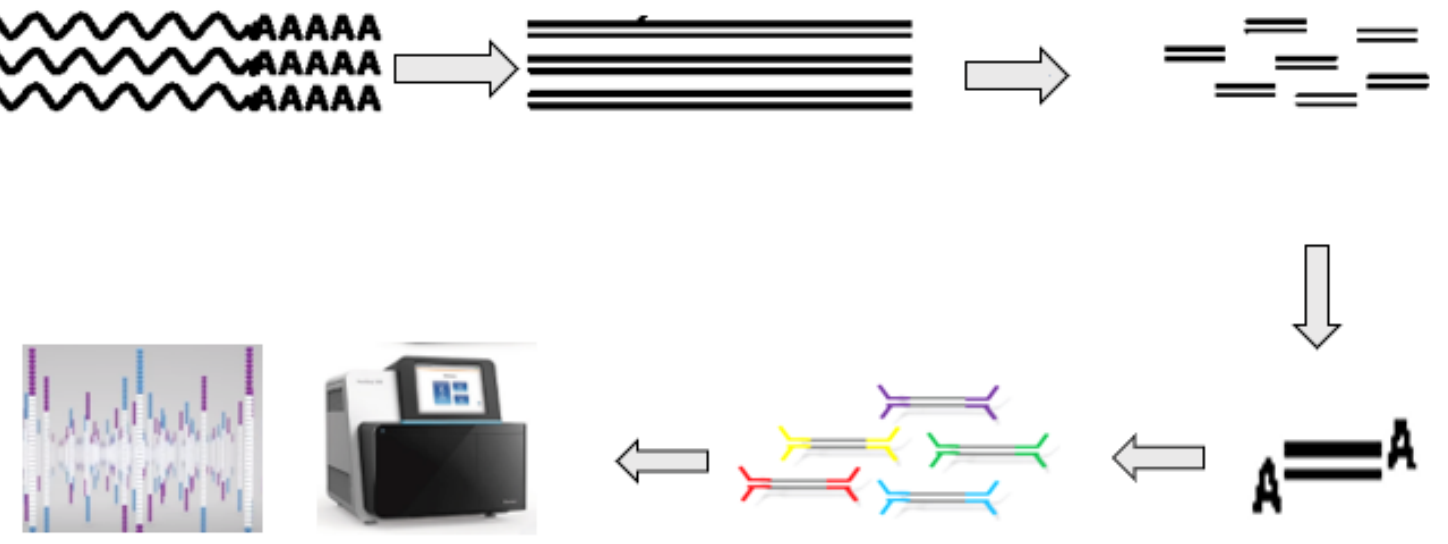

6. Cluster amplification, Illumina sequencing and Generation of RNA Seq

\section{Addition of adapter with 96 unique bar code and 96 seq}

\section{End repair} and ' $A$ ' addition

Figure 1. The work flow of transcriptome sequencing by Illumina platform

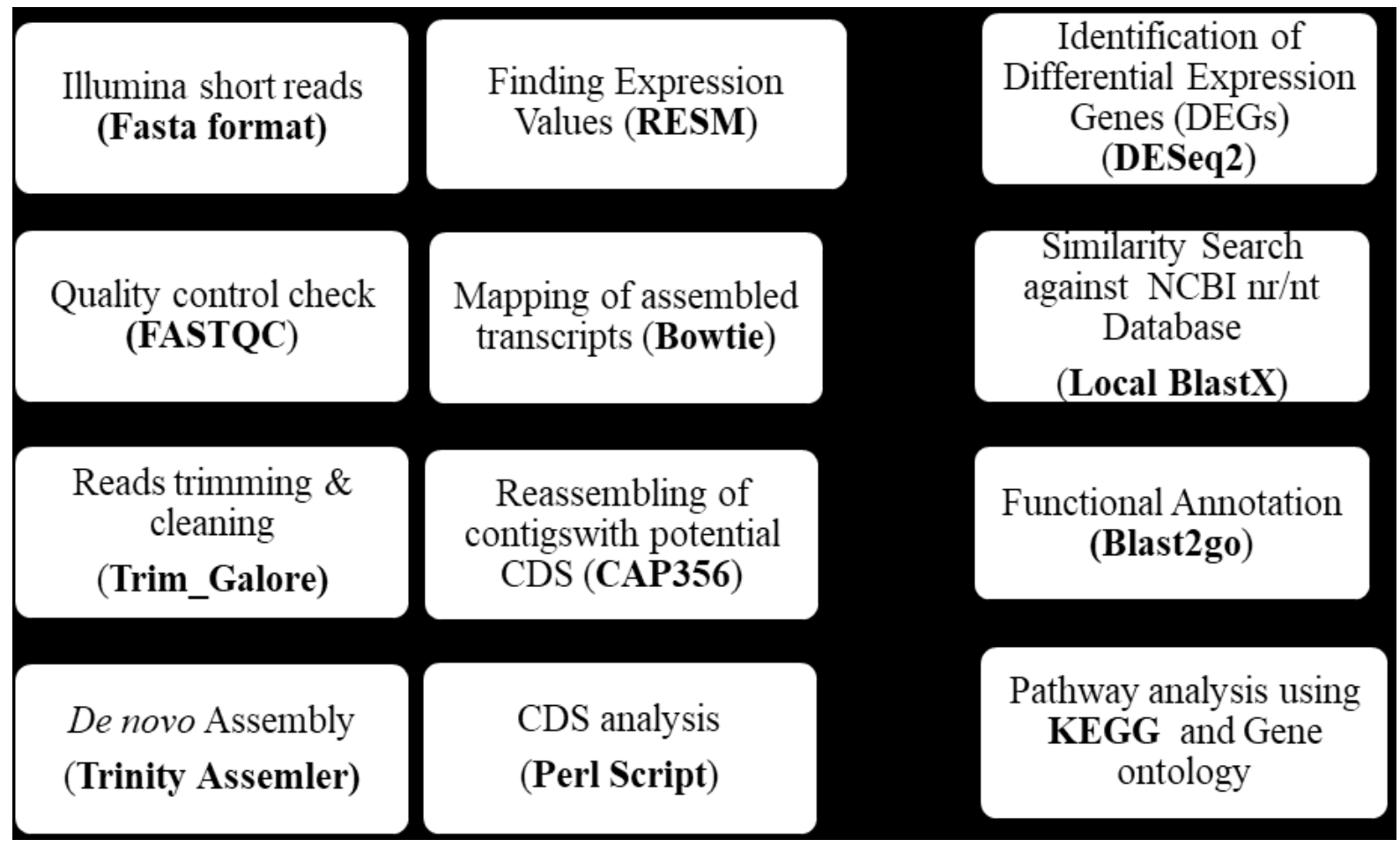

Figure 2. Flow diagram for bioinformatic analysis of transcriptomic sequencing data of C. globosum

\section{Bioinformatic analysis}

After visualization and checking the reads in Fast QC, the contaminants were removed using Trimmomatic tool version 0.30 . The high quality filtered paired reads obtained from $\mathrm{Cg} 2$ and BS112 samples were used as an input for assembly of the transcriptome. De novo assembly of all $\mathrm{Cg} 2$ samples and BS1 12 samples total reads was performed by using trinity assembler V2.4.0. The individual assembled sequences were clustered using CD-HIT (version 4.6) to remove redundancy at $90 \%$ sequence similarity. Unigenes were extracted using the inbuilt trinity perl script. The final assembled transcripts were used for further downstream analysis. The work flow for 
whole analysis of RNA seq data for identification of DEGs with its functional annotation was depicted in Figure 2.

\section{pathways analysis}

The functional annotation of individual and combined unigenes of samples was performed by aligning those unigenes to NR (non-redundant) protein database (version nr.36) of NCBI using BLASTX V 2.2.31. Further, the predicted proteins were subjected to pathway analysis using KEGG (Kyoto Encyclopaedia of Genes and Genomes) (Ogata et al., 1999) database to map the proteins involved in biochemical pathways. The predicted proteins were categorized into three different functional groups such as Biological Process (BP), Molecular Function (MF) and Cellular Component (CC) with default parameters. Finally, the significant gene ontology terms having a False Discovery Rate (FDR) value $\leq 0.05$ and $\mathrm{P}$-value less than $0.01(\mathrm{P}<0.01)$ was used as the threshold to evaluate significant enrichment (Maere et al., 2005). Antibiotic biosynthesis, enzymes and signaling genes were filtered from significant differential genes ( $\log 2 \mathrm{FC}$ and pval0.01). Copy Number Variation (CNV) analysis was done using CNVKit ToolKit to infer and visualize copy number from high-throughput sequencing data (cnvkit-import rna) (https://cnvkit.readthedocs.io/en/stable/ rna.html). Scatter, and genematrics were used to generate plots. The significant enriched biological components were used for network construction and its biological relationship of genes with associated pathways was deciphered by Cytoscape R packages (version: 3.7.2) (Kohl et al., 2011). The statistical charts, gene ontology graphs, pie and bar charts were generated by using Blast2GO to monitor, visualize and evaluate the biological function of the specific gene in C. globosum at a macro level. MapMan was used for visualization and profiling of data sets. To decipher protein -protein association network and its functional interaction, Protein-Protein Interaction Networks Functional Enrichment Analysis was done by using STRING v11 (STRING, http:// www.string-db.org/) to achieve a comprehensive and global interacting gene network, including functional interactions (Szklarczyk et al., 2019).

\section{RESULTS AND DISCUSSION}

\section{In vitro efficacy of $C$. globosum (Cg2) against different pathogens of wheat and rice}

Inhibition percentage of various seed and soil borne pathogens of wheat and rice crops in presence of C. globosum isolate $\mathrm{Cg} 2$ was performed by dual culture techniques (Dennis and Webster, 1971). Among the tested pathogens, C. globosum isolate $\mathrm{Cg} 2$ showed maximum inhibitions of $75.54 \%$ against $B$. sorokiniana followed by $T$. inidca which showed $71.01 \%$ mycelial inhibition. It was also able to inhibit growth of other pathogens like A. alternata (67.20\%), B. oryzae (66.66\%), A. triticina (65.54\%) F. fujikuroi (65.54\%), R. solani $(63.03 \%)$ and F. graminearum (57.72\%) (Table 1, Figure 3). Inhibition percentage of the test pathogens in the presence of C. globosum $(\mathrm{Cg} 2)$ by dual culture technique is shown in Figure 3. Many basic research papers have been published related to the antagonistic activity of $C$. globosum (Biswas et al., 2000; Soytong et al., 2001 and Aggarwal et al., 2004; Aggarwal, 2015). Antibiosis was the most prevalent mechanism of action of $C$. globosum against $B$. sorokiniana (Aggarwal et al. 2004). Chaetomium spp. produces a variety of bioactive metabolites which suppress the growth of many soil and seed-borne phytopathogens. Some of these positive effects have been related to the microbial release of bioactive metabolites and elicitor proteins in the plant rhizosphere (Harman et al., 2004). Present study revealed that under in vitro dual tests, C. globosum $(\mathrm{Cg} 2)$ significantly inhibited the growth of the $B$. sorokiniana and other pathogen by producing clear inhibition zone when compared with the control. Twelve days after incubation, the percentage inhibition over control was $71.4 \%$ for B. sorokiniana (Figure 4 ).

\section{CNV analysis}

Transcriptome analysis showed significant differential gene expression in $C$. globosum during challenge with B. sorokiniana. A total of $14366(\log 2 \mathrm{FC}$ and pval0.01) Differentially Expressed Genes (DEGs) were detected. The top significant encoding gene with $\log 2$-fold changes such as phosphoribosyl aminoimidazole carboxylase (9.693), protease (8.18), ABC transporter-like protein (7.8), cyanate hydratase (Cyanase) (6.7) and Fe2OG dioxygenase domaincontaining protein (5.9) were overrepresented in Cg2-BS112 interaction. In addition to that some other genes like superoxide dismutase (5.55), glycosidase (5.34), carboxylic ester hydrolase (5.27), mannitol-1-phosphate 5-dehydrogenase (M1PDH) (4.92), C2H2-type domain-containing protein (4.46), alpha-1,2-Mannosidase (4.44), alpha-1,4 glucan

Table 1. Inhibition percentage of seed and soil borne fungal pathogens of wheat and rice crops by potential isolate C. globosum (Cg2)

\begin{tabular}{|l|l|l|l|}
\hline \multirow{2}{*}{$\begin{array}{l}\text { NL } \\
\text { No }\end{array}$} & \multirow{2}{*}{ Pathogen } & \multicolumn{2}{|l|}{ C.globosum (Cg2) } \\
\cline { 3 - 4 } & & $\begin{array}{l}\text { Inhibition } \\
\text { over control } \\
\text { (cm) }\end{array}$ & $\begin{array}{l}\text { \% inhibition } \\
\text { over control } \\
(\%)\end{array}$ \\
\hline 1 & Bipolaris sorokiniana & 6.82 & 75.54 \\
\hline 2 & Bipolaris oryzae & 6.05 & 66.66 \\
\hline 3 & Fusarium fujikuroi & 5.92 & 65.54 \\
\hline 4 & Rhizoctonia solani & 5.73 & 63.03 \\
\hline 5 & Alternaria triticina & 5.95 & 65.62 \\
\hline 6 & Alternaria alternata & 6.01 & 67.20 \\
\hline 7 & Fusarium graminearum & 5.52 & 57.72 \\
\hline 8 & Tilletia indica & 6.4 & 71.01 \\
\hline
\end{tabular}




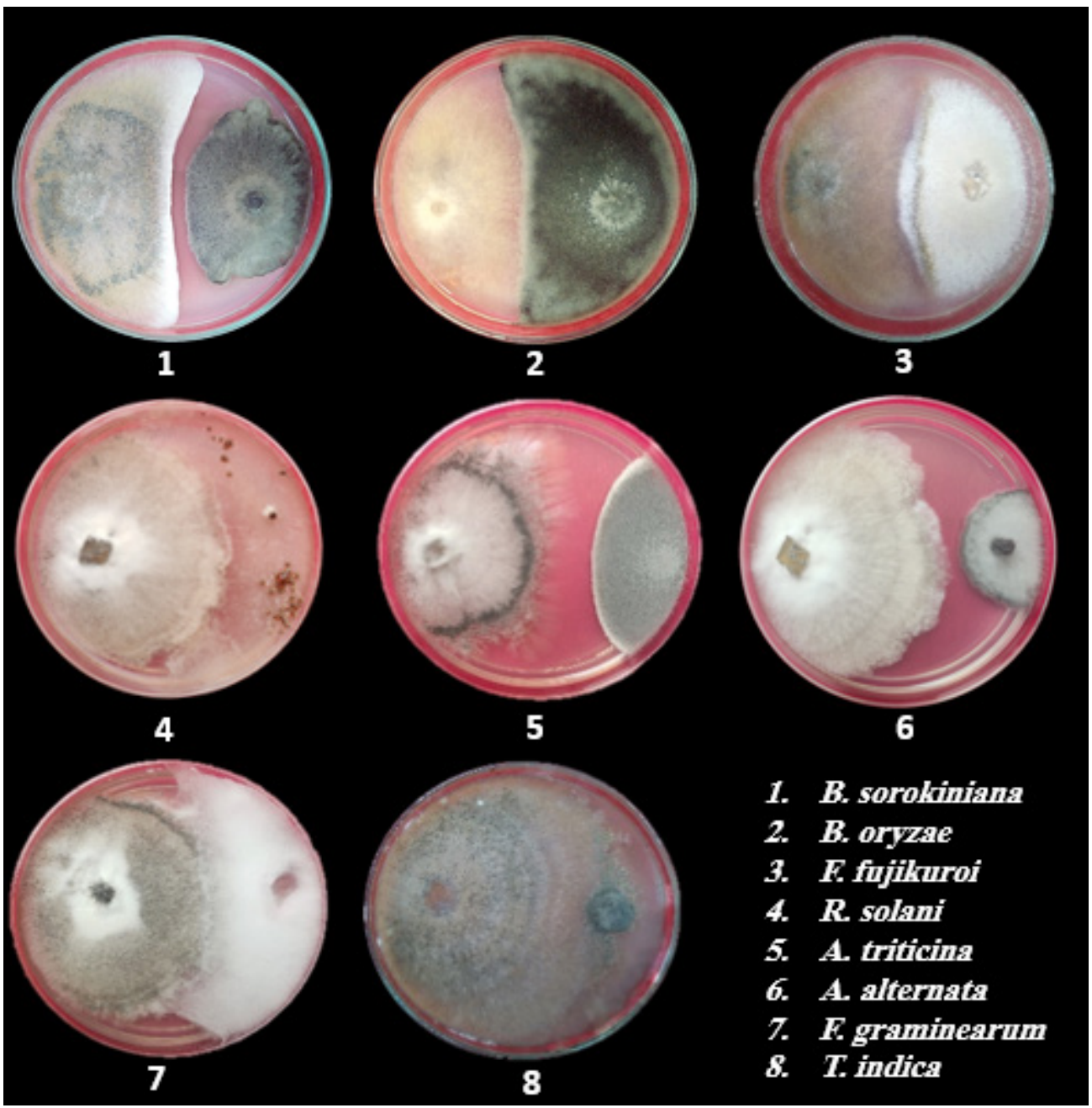

Figure 3. Dual culture plate showing antagonistic activity of Chaetomium globosum (Cg2) against seed and soil borne fungal pathogens of wheat and rice

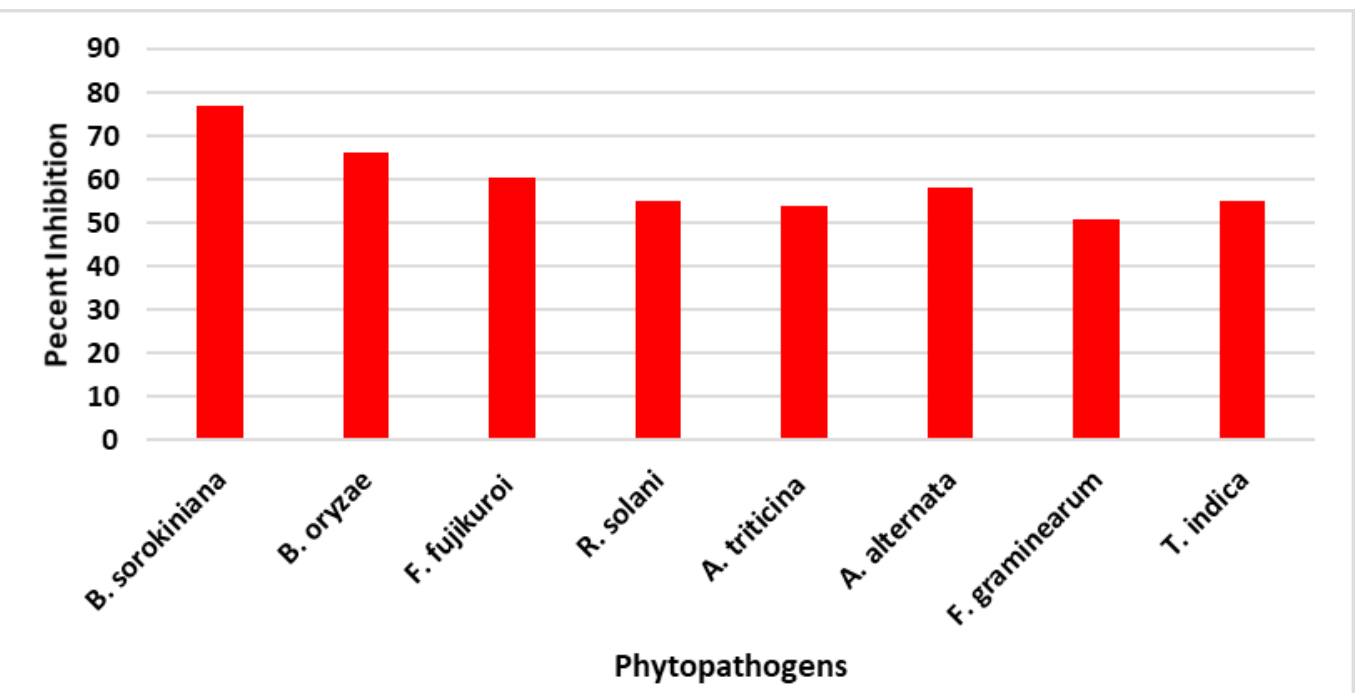

Figure 4. Percent inhibition of mycelial growth of different seed and soil borne fungal pathogens of wheat and rice by $C$. globosum (Cg2) 
Deciphering the network of interconnected pathways of Chaetomium globosum antagonistic genes against Bipolaris sorokiniana

phosphorylase (3.99), endo-chitinase (3.87), MFS domaincontaining protein (3.85), P53-like transcription factor (Fragment) (3.55), metalloprotease (3.4), polyketide synthase (3.35), catalase-peroxidase (CP)/ peroxidase/catalase) (3.14), protein kinase domain-containing protein (3.18) and glutamate decarboxylase (2.1) were expressed in Cg2-BS112 interaction when compared with $\mathrm{Cg} 2$ control (Table 2).

The selected potential antagonistic gene previously validated was subjected $\mathrm{CNV}$ analysis. It clearly depicts that the genes encoding MFS domain-containing protein (TRINITY DN7412_c1_g1_i6), Phosphoribosyl aminoimidazole carboxylase Protein (TRINITY_DN7744_c3_g7_i2), Protein Kinase domain-containing protein (TRINITY_DN7566_ c2_g2_i12), Glycosidase (TRINITY_DN7787_c5_g3_i1), Superoxide dismutase (TRINITY_DN7807_c0_g1_i1) and Mannitol-1-phosphate 5-dehydrogenase (TRINITY DN7971_c2_g2_i1) were expressed significantly in Cg2BS112 interaction when compared with $\mathrm{Cg} 2$ control.
It indicated the positive correlation of differential transcriptional level and $\mathrm{CNV}$ in general. But the copy ratio of above-mentioned genes was significantly lower which is clearly shown in Figure 5. But in $\mathrm{Cg} 2$ control, the expression of the above-mentioned genes was significantly lower and it signifies that, decrease in the copy number of potential genes in control. Remarkably, for substantial number of genes, their copy numbers exert a positive correlation with the corresponding differential gene expression. Interestingly, gene-wise copy number amplification appears correlated with enhanced gene expression in Cg2-BS112 interaction when compared with $\mathrm{Cg} 2$ control, while copy number deletion usually led to decreased gene expression of selected potential genes in $\mathrm{Cg} 2$ control. Similar results were reported by Lind et al. (2017) where they studied extensive genetic variation in Aspergillus fumigatus secondary metabolic clusters and suggested that gene $\mathrm{CNV}$ in these regions could contribute to individual variation in secondary metabolite production.

Table 2. Categorization of top significant encoding genes with log 2-fold changes in Cg2-BS112 interaction against Cg2 control

\begin{tabular}{|c|c|c|c|c|c|c|c|}
\hline \multirow{2}{*}{ Chromosome } & \multirow{2}{*}{ Gene } & \multirow{2}{*}{ Start } & \multirow{2}{*}{ End } & \multicolumn{2}{|c|}{ Cg2-BS112 Interaction } & \multicolumn{2}{|c|}{ Cg2 Control } \\
\hline & & & & Depth & $\log 2$ & Depth & $\log 2$ \\
\hline TRINITY_DN7744_c3_g7_i2 & $\begin{array}{l}\text { Phosphoribosyl aminoimidazole } \\
\text { carboxylase }\end{array}$ & 1 & 264 & 47395.4 & 9.69331 & 44.0682 & 1.65683 \\
\hline TRINITY_DN7674_c8_g3_i2 & Protease & 1863 & 2129 & 18339.4 & 8.18583 & 0 & -23.8048 \\
\hline TRINITY_DN8092_c3_g3_i5 & $\mathrm{ABC}$ transporter-like protein & 5528 & 5792 & 38434 & 7.80027 & 0 & -23.8048 \\
\hline TRINITY_DN7750_c11_g3_i1 & Cyanate hydratase (Cyanase) & 2140 & 2407 & 23115.6 & 6.73794 & 0 & -23.8048 \\
\hline TRINITY_DN7464_c5_g1_i4 & $\begin{array}{l}\text { Fe2OG dioxygenase domain-con- } \\
\text { taining protein }\end{array}$ & 1339 & 1606 & 39883.1 & 5.98568 & 0 & -23.8048 \\
\hline TRINITY_DN7807_c0_g1_i1 & Superoxide dismutase & 291 & 581 & 14255.4 & 5.55786 & 16.0224 & 0.53709 \\
\hline TRINITY_DN7787_c5_g3_i1 & Glycosidase & 1 & 270 & 7355.22 & 5.34402 & 0 & -23.8048 \\
\hline TRINITY_DN7946_c4_g3_i1 & Carboxylic ester hydrolase & 5519 & 5782 & 6672.71 & 5.27128 & 0 & -23.8048 \\
\hline TRINITY_DN7971_c2_g2_i1 & $\begin{array}{l}\text { Mannitol-1-phosphate 5-dehydroge- } \\
\text { nase (M1PDH) }\end{array}$ & 1 & 271 & 3690.14 & 4.92671 & 0.237037 & -5.54174 \\
\hline TRINITY_DN7776_c2_g8_i3 & $\begin{array}{l}\mathrm{C} 2 \mathrm{H} 2 \text {-type domain-containing } \\
\text { protein }\end{array}$ & 805 & 1073 & 2849.54 & 4.46275 & 0 & -23.8048 \\
\hline TRINITY_DN7658_c6_g5_i2 & Alpha-1,2-Mannosidase & 265 & 530 & 8975.29 & 4.45277 & 0 & -23.4649 \\
\hline TRINITY_DN7581_c4_g1_i2 & Alpha-1,4 glucan phosphorylase & 1074 & 1342 & 4611.26 & 3.99241 & 0 & -23.4649 \\
\hline TRINITY_DN7969_c3_g1_i1 & End chitinase & 535 & 802 & 9238.81 & 3.87906 & 0.543071 & -4.34571 \\
\hline TRINITY_DN7412_c1_g1_i6 & MFS domain-containing protein & 1775 & 2029 & 3848.41 & 3.85034 & 0 & -23.4649 \\
\hline TRINITY_DN7704_c1_g5_i10 & $\begin{array}{l}\text { P53-like transcription factor (Frag- } \\
\text { ment) }\end{array}$ & 4983 & 5245 & 3882.04 & 3.55838 & 0 & -23.4649 \\
\hline TRINITY_DN7747_c4_g1_i2 & Metalloprotease & 1312 & 1574 & 2675.15 & 3.40872 & 0 & -23.8048 \\
\hline TRINITY_DN7358_c2_g1_i2 & Polyketide synthase & 1054 & 1317 & 2251.39 & 3.35696 & 0 & -23.8048 \\
\hline TRINITY_DN7146_c0_g3_i2 & $\begin{array}{l}\text { Catalase-peroxidase (CP)/ Peroxi- } \\
\text { dase/catalase) }\end{array}$ & 8730 & 8995 & 3586.55 & 3.14476 & 0 & -23.4649 \\
\hline TRINITY_DN7566_c2_g2_i12 & $\begin{array}{l}\text { Protein kinase domain-containing } \\
\text { protein }\end{array}$ & 1062 & 1327 & 1441.74 & 3.18238 & 65.9472 & 2.57831 \\
\hline TRINITY_DN7551_c2_g4_i5 & Glutamate decarboxylase & 1598 & 1864 & 2403.03 & 2.10551 & 0 & -23.8048 \\
\hline
\end{tabular}



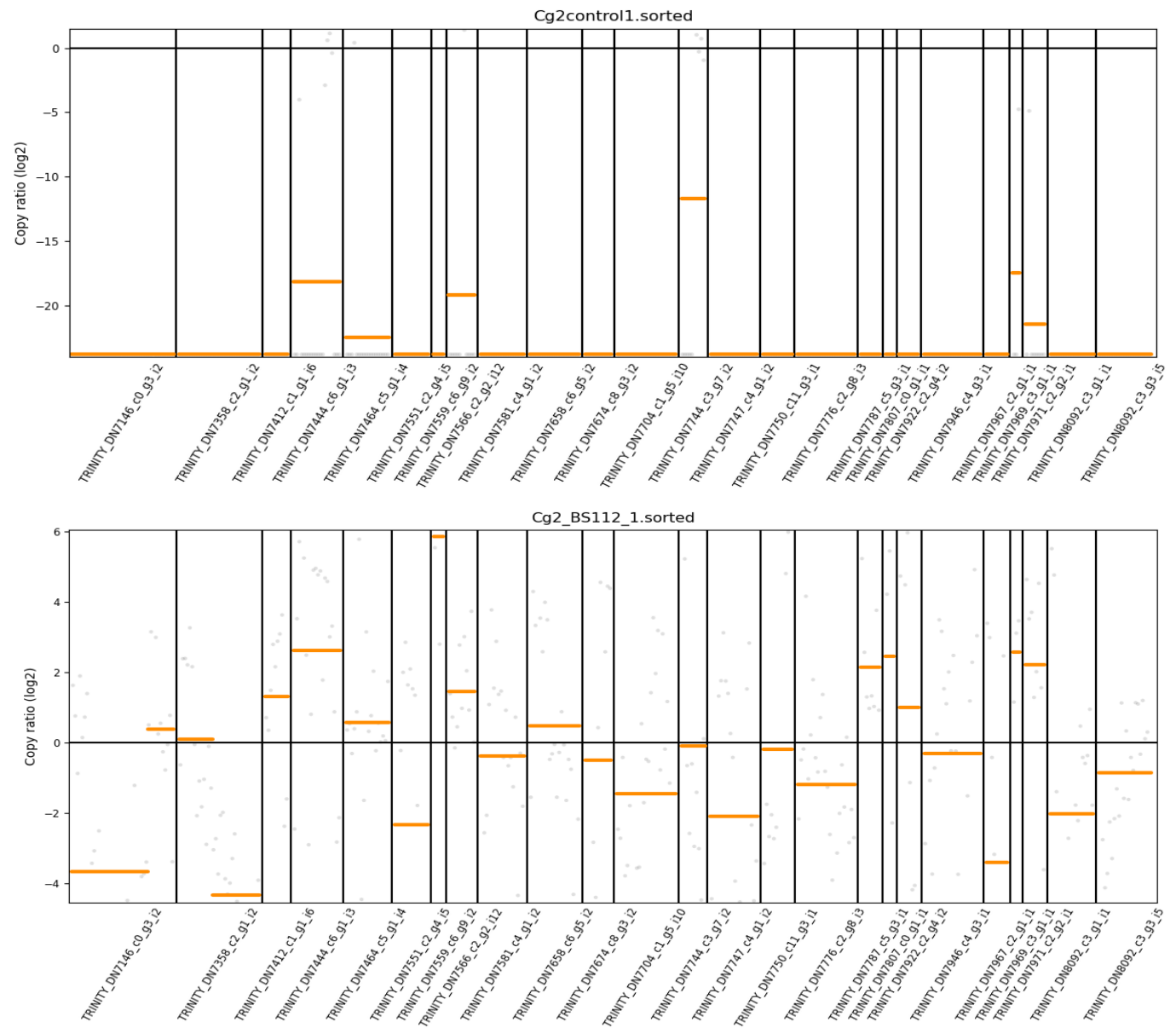

Figure 5. Copy ratio comparisons of selected potential antagonistic related genes in $\mathrm{Cg} 2-\mathrm{BS} 112$ interaction and $\mathrm{Cg} 2 \mathrm{control}$

\section{Exporing the network of interconnected pathways in C. globosum}

The genes involved in cell wall degradation viz. glycoside hydrolase family consisting of GH1, GH3, GH5, GH 13, GH16, GH17, GH18, GH31, GH32, GH76, GH 78, GH 92, and $\mathrm{GH}$ family protein were expressed and interconnected in Cg2-BS112 interaction (Figure 6), which suggested a central role for them in C. globosum antagonisms, probably during host fungal cell wall degradation and mycelial inhibition. In addition, glucanase, glutamate synthase were also expressed. But in $\mathrm{Cg} 2$ control conditions, only glycoside hydrolase family GH 5 was associated (Figure 6). The combination of Glycoside Hydrolase family (GHs) seems to be preferentially associated with mycoparasitism-related conditions in $T$. harzianum (Monteiro et al., 2010; Vieira et al., 2013). Several fungi produce a variety of Carbohydrate Activity enzymes (CAZymes) for the degradation of plant polysaccharide materials to facilitate infection and/or gain nutrition. Tiwari et al. (2013) explored the role of -Glucosidases from the fungus Trichoderma as an efficient cellulase machinery for cell wall degradation of several plant pathogens. Grabowska et al., (2012) reported the essential role of glutamate synthase in the metabolism of nitrogen by catalysing the condensation of glutamate and ammonia to form glutamine which acts as a source of nitrogen for its growth and development. Walsh et al., (2000) reported that, the cyanate generated ammonium can serve as a source of nitrogen for growth of C. globosum.

Similarly, antibiosis was the most prevalent antagonistic mechanism of C. globosum against B. sorokiniana in agreement with studies by Aggarwal et al. (2004). In present analysis, triterpenoid (terpene cyclase, terpene synthase activity [GO:0010333]), alkaloids (aminotran_1_2 domaincontaining protein), phospholipase, transketolase, amino acid transferase, phosphotransferase, S-hydroxymethyl glutathione dehydrogenase, amidophosphoribosyltransferase, isocitrate lyase and aspartate amino transferase (biosynthesis of antibiotics), phosphotransferase, succinate dehydrogenase, acetyl co-enzyme A synthase, thiolase family, catalase, serine hydroxy methyl transferase, malate dehydrogenase and methoxy-polyprenyl benzoquinol methylase (biosynthesis of secondary metabolites; ubiquinone and other terpenoidquinone biosynthesis) were expressed significantly in $C$. globosum $\mathrm{Cg} 2$ when exposed to B. sorokiniana (Figure 


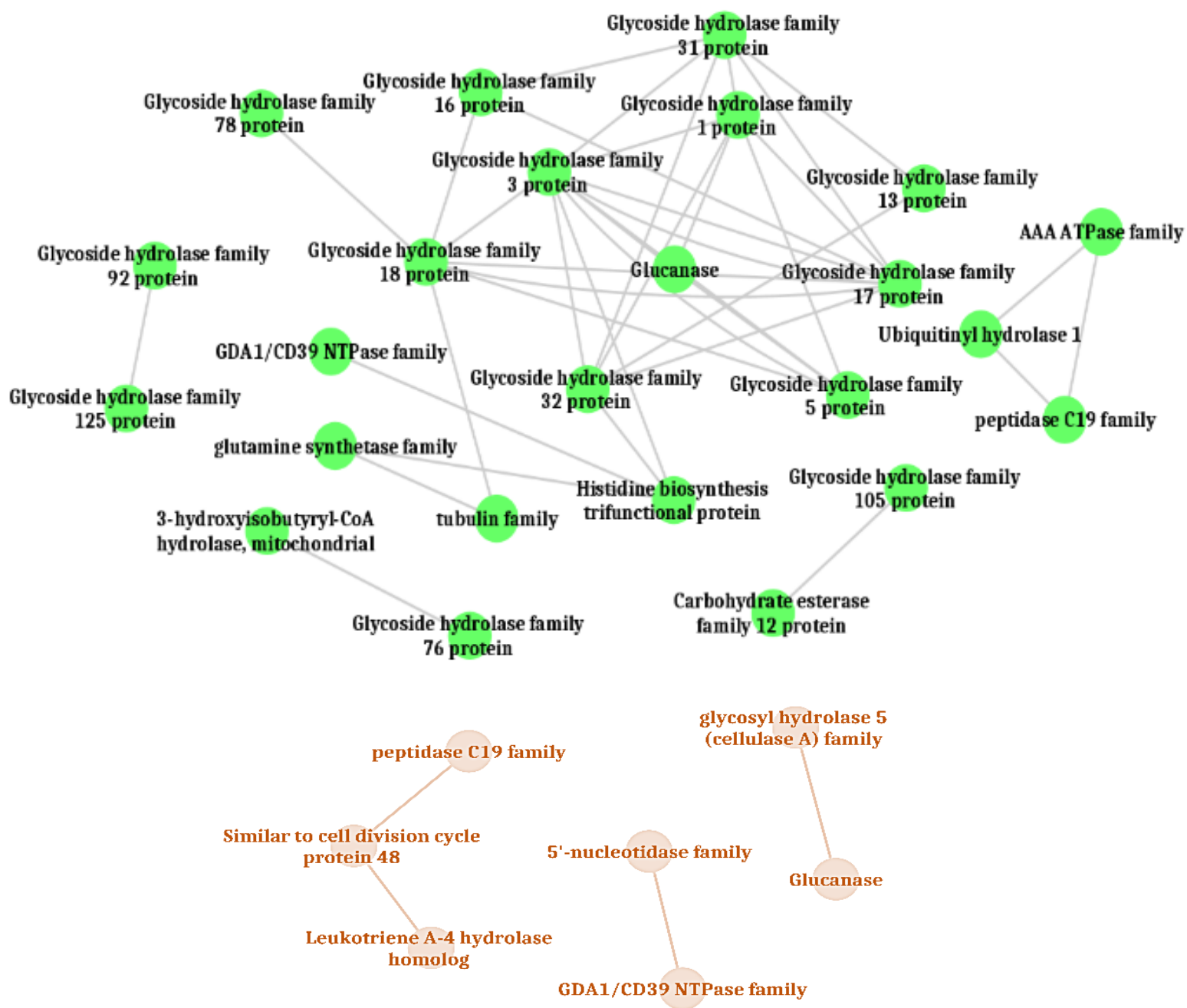

Figure 6. Hydrolase interconnected pathways involved in antagonism of Chaetomium globosum (Cg2) upon challenge with B. sorokiniana (BS112). A) Cg2-BS112 interaction B) Cg2 control

7). Similar investigation was reported earlier by Shentu et al. (2014) who evaluated the role of terpenoid backbone biosynthesis in Trichoderma brevicompactum biocontrol mechanism.

A large number of genes like TRAM domain-containing protein (CHGG_10433), RRM domain-containing protein (CHGG_10382), Utp12 domain-containing protein (CHGG_10621), Protein SDA1(CHGG_10486), CTP synthase (CHGG_11054), Chorismate synthase (CHGG_10505), Threonine dehydratase (CHGG_10834), Epimerase domain-containing protein (CHGG_10579), Pyruvate carboxyltransferase domain-containing protein (CHGG_1071), Epimerase domain-containing protein (CHGG_10579), Poly [ADP-ribose] polymerase (PARP) (CHGG_10788), RPOLD domain-containing protein (CHGG_10417), FHA domain-containing protein (CHGG_10861), Protein kinase domain-containing protein (CHGG_10629), RING-type domain-containing protein (CHGG_10844), RBR-type E3 ubiquitin transferase (CHGG_10570), E3 ubiquitin-protein ligase PEP5 (CHGG_10507), Tr-type G domain-containing protein (XP_007701615.1), MPN domain-containing protein (XP_007699947.1), Nop domain-containing protein (XP_007695297.1), J domain-containing protein (XP_007703546.1), zf-LYAR domain-containing protein (XP_007702390.1), Obg-like ATPase 1 (XP_007702860.1) were interconnected with each other in interaction (Fig. 8 ). But the expression of these genes in control is lower. A similar study has been conducted by Kosanovic et al. (2013) in the interaction of Pseudomonas putida and Pseudomonas tolaasii with Trichoderma aggressivum. Further studies for functional characterization of candidate genes mentioned here are necessary in order to better define the exact pathways involved in mycoparasitism and antibiosis in C. globosum. 


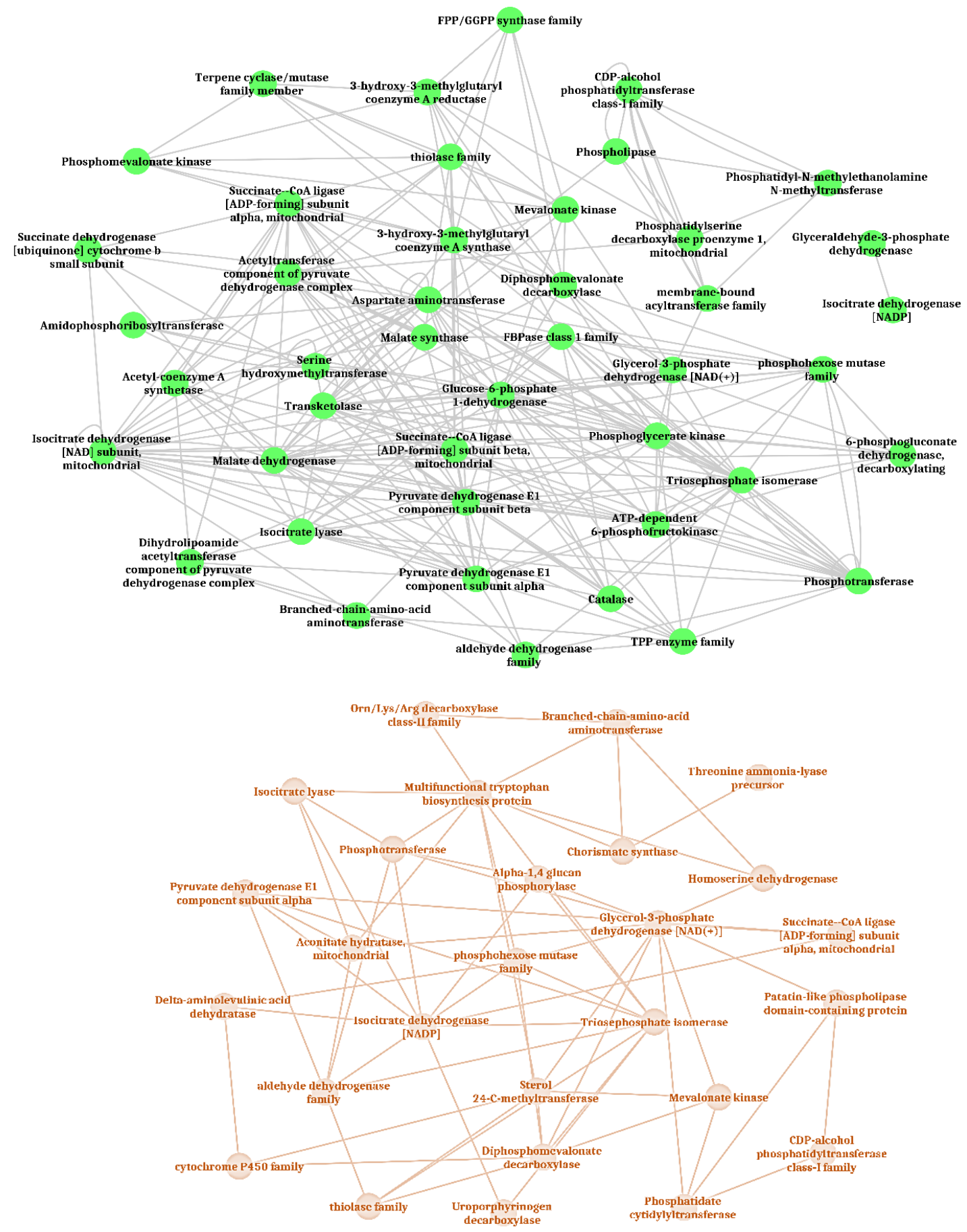

Figure 7. Secondary metabolite interconnected pathways involved in antibiosis of $C$. globosum (Cg2) upon challenge with $B$. sorokiniana (BS112). A) Cg2-BS112 interaction B) Cg2 control 


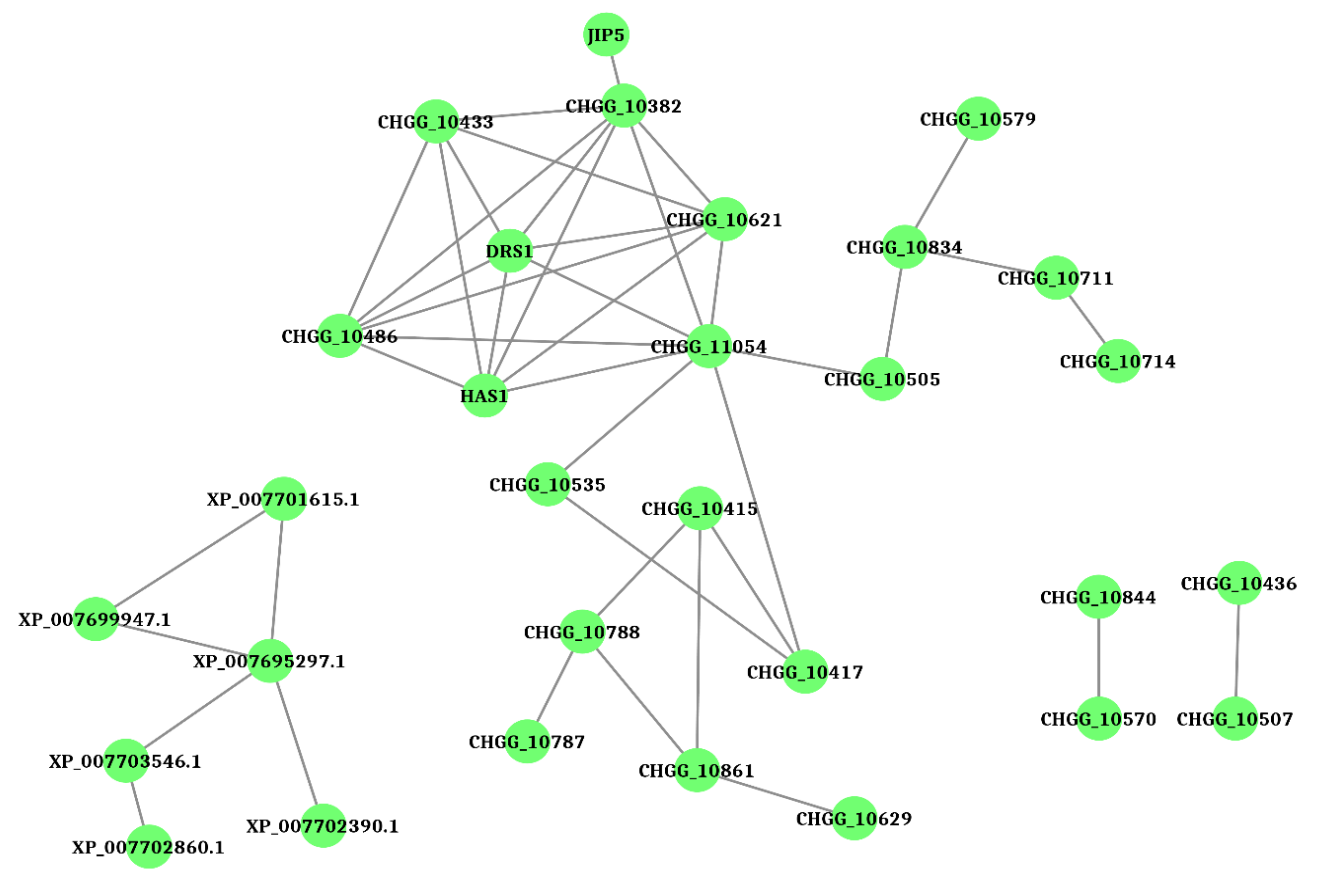

Figure 8. STRING analysis of top differentially expressed proteins present in C. globosum (Cg2) upon challenge with B. sorokiniana (BS112)

\section{CONCLUSION}

This study demonstrated the efficacy of Chaetomium globosum in controlling several plant pathogens. Interconnected pathways related to biosynthesis of secondary metabolites, hydrolytic enzymes and other key regulator genes were involved in the production of hydrolytic enzymes and antifungal metabolites in C. globosum. The extent of inhibition by $C$. globosum provides its wide usage in the management of plant pathogens in sustainable agriculture. The obtained data will greatly enrich the current $C$. globosum genetic information and provide a good foundation for better understanding of the molecular mechanism of C. globosum against plant pathogens.

\section{ACKNOWLEDGEMENTS}

The authors are thankful to the PGS and Director, ICARIARI, New Delhi, for providing financial assistance through World Bank sponsored NAHEP-CAAST project. Authors also acknowledge the support from Head, Division of Plant Pathology, ICAR-IARI, New Delhi for necessary facilities in carrying out this work smoothly.

\section{REFERENCES}

Aggarwal R. 2015. Chaetomium globosum: A potential biocontrol agent and its mechanism of action. Indian Phytopathol. 68(1): 8-24.
Aggarwal R, Kharbikar LL, Sharma S, Gupta S and Yadav A. 2013. Phylogenetic relationships of Chaetomium isolates based on the internal transcribed spacer region of the rRNA gene cluster. Afr J Biotechnol. 12(9): 91420. doi: $10.5897 /$ ajb12.2633

Aggarwal R, Tewari AK, Srivastava KD, Singh DV. 2004. Role of antibiosis in the biological control of spot blotch (Cochliobolus sativus) of wheat by Chaetomium globosum. Mycopathologia. 157(4): 369-77. PMid: 15281398. https://doi:10.1023/b: myco.0000030446 https://doi.org/10.1023/ B:MYCO.0000030446.86370.14

Biswas SK, Srivastava KD, Aggarwal R, Dureja P, Singh DV. 2000. Antagonism of Chaetomium globosum to Drechslera sorokiniana, the spot blotch pathogen of wheat. Indian Phytopathol. 53: 436-40. doi:10.1023/b: myco.0000030446.86370.14

Dal Bello GM, Monaco CI, Sisterna MN. 1994. Efecto de Trichoderma spp. sobre el control del tizón de la plántula en trigo ocasionada por Bipolaris sorokiniana. Fitopatol Bras 19: 394-400.

Darshan K, Rashmi Aggarwal, Bashyal BM, Singh J, Shanmugam V, Gurjar MS, Solanke A. 2020. Transcriptome profiling provides insights into potential antagonistic mechanisms involved in Chaetomium globosum against Bipolaris 
DARSHAN et al.

sorokiniana. Front Microbial. 11: e578115. PMid: 33365017 PMCid: PMC7750538. https://doi. org/10.3389/fmicb.2020.578115

Doveri F. 2013. An additional update on the genus Chaetomium with descriptions of two coprophilous species, new to Italy. Mycosphere. 4: 820-46. doi. org/10.5943/mycosphere/4/4/17 https://doi.org/10.5943/ mycosphere/4/4/17

Grabowska A, Kwinta J, Bielawski W. 2012. Glutamine synthetase and glutamate dehydrogenase in triticale seeds: Molecular cloning and genes expression. Acta Physiol Plant. 34(6): 2393-406. doi: 10.1007/s11738012-1085-9 https://doi.org/10.1007/s11738-012-1085-9

Grabowska P, Misra BN, Sangwan NS. 2013. $\beta$-glucosidases from the fungus Trichoderma: An efficient cellulase machinery in biotechnological applications. BioMed Res. Inter. 1: 1-10. PMid: 23984325 PMCid: PMC3747355. doi: 10.1155/2013/203735 https://doi. org/10.1155/2013/203735

Harman GE, Howell CR, Viterbo A, Chet I, Lorito M. 2004. Trichoderma species-opportunistic, avirulent plant symbionts. Nat Rev Microbiol. 2(1): 43-56. PMid: 15035008. doi:10.1038/nrmicro797 https://doi. org/10.1038/nrmicro797

Howell CR. 2003. Mechanisms employed by Trichoderma species in the biological control of plant diseases: The history and evolution of current concepts. Plant Dis 87(1): 4-10. PMid: 30812698. doi: 10.1094/pdis.2003.87.1.4 https://doi.org/10.1094/PDIS.2003.87.1.4

Kohl M, Wiese S, Warscheid B. 2011. Cytoscape: Software for visualization and analysis of biological networks. Data Mining in Proteomics. Methods Mol Biol. 696: 291-303. PMid: 21063955. doi: 10.1007/978-1-60761-987-1_18 https://doi.org/10.1007/978-1-60761-987-1_18

Kosanovic DI, Potocnik B, Duduk J, Vukojevic M, Stajic E, Rekanovic, S Milijasevic-Marcic. 2013. Trichoderma species on Agaricus bisporus farms in Serbia and their biocontrol. Ann Appl Biol. 163(2): 218-30. https://doi. org/10.1111/aab.12048

Lind Abigail L, Jennifer H, Lameiras WC, Wiemann P, Palmer JM, Keller NP, Rodrigues F, Goldman GH, Rokas A. 2017. Drivers of genetic diversity in secondary metabolic gene clusters in a fungal population. BioRxiv. 149856. https://doi.org/10.1101/149856

Maere S, Heymans K, Kuiper M. 2005. BiNGO: A Cytoscape plugin to assess over representation of gene ontology categories in biological networks. Bioinformatics. 21: 34489. PMid: 15972284. https://doi.org/10.1093/ bioinformatics/bti551

Mandal SK, Srivastava D, Aggarwal R, Singh DV. 1999. Mycoparasitic action of some fungi on spot blotch pathogen Drechslera sorokiniana of wheat. Indian Phytopathol. 52: 39-43.

Monteiro VN, do Nascimento Silva R, Steindorff AS, Costa FT, Noronha EF, Ricart CAO, Ulhoa CJ. 2010. New insights in Trichoderma harzianum antagonism of fungal plant pathogens by secreted protein analysis. Curr Micro 61(4): 298-305. PMid: 20213103. https://doi.org/10.1007/s00284-010-9611-8

Moya P, Pedemonte D, Amengual, S, Franco ME, Sisterna MN. 2016. Antagonism and modes of action of Chaetomium globosum species group, potential biocontrol agent of barley foliar diseases. Bol Soc Argent Bot. 51(4): 56978. https://doi.org/10.31055/1851.2372.v51.n4.16334

Ogata H, Goto S, Sato K, Fujibuchi W, Bono H, Kanehisa M. 1999. KEGG: Kyoto encyclopedia of genes and genomes. Nucleic Acids Res. 27(1): 29-34. PMid: 9847135 PMCid: PMC148090. doi: 10.1093/nar/27.1.29 https://doi.org/10.1093/nar/27.1.29

Shentu XP, Liu WP, Zhan XH, Xu YP, Xu JF, Yu XP, Zhang CX. 2014. Transcriptome sequencing and gene expression analysis of Trichoderma brevicompactum under different culture conditions. PloS One. 9(4): e94203. PMid: 24710600 PMCid: PMC3978026. https://doi.org/10.1371/journal.pone.0094203

Soytong K, Kanokmedhakul S, Kukongviriyapa V, Isobe M. 2001. Application of Chaetomium species (Ketomium) as a new broad-spectrum biological fungicide for plant disease control. Fungal Divers. 7:1-15.

Szklarczyk D, Gable AL, Lyon D, Junge A, Wyder S, Huerta-Cepas J, Jensen LJ. 2019. STRING v11: Proteinprotein association networks with increased coverage, supporting functional discovery in genome-wide experimental datasets. Nucleic Acids Res.47: D607613. PMid: 30476243 PMCid: PMC6323986. https:// doi.org/10.1093/nar/gky1131

Vannacci G, Harman GE. 1987. Biocontrol of seed-borne Alternaria raphani and A. brassicicola. Can J Microbiol. 33(10): 850-6. https://doi.org/10.1139/m87-149

Vieira PM, Coelho ASG, Steindorff AS, de Siqueira, SJL, do Nascimento Silva R, Ulhoa CJ. 2013. Identification of differentially expressed genes from Trichoderma 
Deciphering the network of interconnected pathways of Chaetomium globosum antagonistic genes against Bipolaris sorokiniana

harzianum during growth on cell wall of Fusarium solani as a tool for biotechnological application. BMC Genomics. 14(1): 177. PMid: 23497274 PMCid: PMC3606605. https://doi.org/10.1186/1471-2164-14177

Walsh MA, Otwinowski Z, Perrakis A, Anderson PM, Joachimiak A. 2000. Structure of cyanase reveals that a novel dimeric and decameric arrangement of subunits is required for formation of the enzyme active site.
Structure. 8(5): 505-14. https://doi.org/10.1016/S09692126(00)00134-9

Wang XW, Lombard L, Groenewald JZ, Li J, Videir SI, Samson RA, Liu XZ, Crous PW. 2016. Phylogenetic reassessment of the Chaetomium globosum species complex. Persoonia. 36: 83-133. PMid: 27616789 PMCid: PMC4988377. https://doi. org/10.3767/003158516X689657 